\title{
Crítica semiótica do populismo ${ }^{1}$
}

\author{
Eric Landowski \\ https://orcid.org/0000-0002-9444-8986 \\ I - Centre National de la Recherche Scientifique \\ Paris, France
}

Resumo: Crítica semiótica do populismo - Como explicar o imenso sucesso atual de líderes populistas tais como J. Bolsonaro, D. Trump ou V. Orban? As explicações sociológicas e políticas fazem apelo a uma série de dados contextuais: a crise econômica, o desemprego, a imigração, a insegurança, atribuídos à falência do sistema político representativo. O objetivo deste artigo é o de completar essas explicações adotando uma perspectiva propriamente semiótica, que consiste em analisar (na imanência) as relações sensíveis, de caráter "íntimo" — pessoalmente, imediatamente, estesicamente vividos — que se estabelecem entre os líderes populistas e seus partidários. O artigo inclui também uma tipologia de regimes políticos (totalitarismo, absolutismo, democracia representativa, democracia "direta" e sua caricatura, a demagogia) interdefinidos com base nos regimes interacionais que lhes estão subjacentes.

Palavras-chave: ajustamento; contágio; democracia; estesia; populismo.

Abstract: A semiotic critique of populism - How to explain the huge success of such populist leaders as J. Bolsonaro, D. Trump ou V. Orban? Sociological interpretations are mainly based on contextual datas: the economic crisis, unemployment, immigration, unsecurity, attributed to the failure of the representative political "system". The aim of this article is to complement these approaches by adopting a specifically semiotic perspective which consists in analysing the kind of almost intimate relationships that populist leaders manage to establish with their supporters. The article also includes a typology of political regimes (totalitarianism, absolutism, representative democracy, "direct" democracy and its caricature, demagogy) which is based on the differenciation between the respective interactional regimes underlying each of them (programming, accident, manipulation, adjustment).

Keywords: adjustment; contagion; democracy; aesthesis; populism.

\section{Explicar o populismo?}

Da Grã-Bretanha à Itália, da Hungria à França ou à Holanda, do Brasil aos Estados Unidos, praticamente todos os países ocidentais foram afetados nestes últimos anos,

1 Artigo inédito em francês, traduzido por Murilo Scóz (partes 1 e 2) e Ana Claudia de Oliveira (partes 3 a 5), com revisão do autor. 
em graus variados, pela "onda populista". Sem discutir a exatidão ou a impropriedade deste termo do ponto de vista da teoria política, o tomamos aqui tal como o encontramos hoje em circulação: como uma etiqueta aplicada a diversas correntes de forte teor nacionalista que têm em comum se apresentar como defensores dos interesses do "povo" (subentendido, exclusivamente aquele do próprio país) e, com esse fim, preconizam ou tomam medidas que não somente vão contra os princípios democráticos mas, também, ameaçam o equilíbrio das relações internacionais. Como tal, o fenômeno merece análise e exige críticas, em particular do ponto de vista semiótico.

É verdade que foram feitos tantos estudos sobre o assunto, que tudo parece já ter sido dito. Será que um olhar semiótico poderia trazer algo mais? De modo geral, as interpretações dos cientistas políticos combinam três fatores explicativos. A "onda" atual se deveria ao fato de que o poder de sedução da ideologia (fator de base) difundida pelos movimentos em questão é hoje reforçado tanto pelo impacto negativo do desenvolvimento socioeconômico (segundo fator) na clientela política visada, quanto por múltiplos dados conjunturais (terceiro fator) - escândalos, ataques terroristas ou desastres naturais - que frequentemente coincidem com os momentos de seus maiores sucessos eleitorais. No entanto, essas interpretações ignoram um quarto fator, cujos mecanismos a semiótica tem mais especificamente a vocação de esclarecer. Esse fator, que oferece a vantagem de explicar diretamente o fervor despertado por líderes como M. Salvini, B. Johnson, J. Bolsonaro, M. Le Pen, V. Orban, D. Trump e outros, é a forma de sua mise en scène. É o modo, basicamente comum a todos eles, pelo qual se apresentam publicamente e o tipo de ligação, por assim dizer "íntima", que eles conseguem estabelecer com seus apoiadores, além ou aquém das medidas concretas que eles ou seus partidos têm de propor².

Identificar a especificidade, as condições e os efeitos desses vínculos quase interpessoais, imediata e intimamente experimentados, que se formam entre líderes populistas e seus públicos, seria dar conta do fenômeno (de acordo com um dos princípios hjelmslevianos que fundam a abordagem semiótica) por uma explicação imanente, ou seja, com base nos dados constitutivos do próprio objeto, na própria relação entre a fonte e o alvo das práticas de encenação "populista". Dessa forma, isso traria elementos de entendimento complementares aos fornecidos pelas abordagens mais correntes, que, por sua vez, privilegiam dados contextuais, sejam eles da ordem da sociologia do eleitorado ou relativos a problemas estruturais como desemprego ou imigração, ou ainda a fatores mais circunstanciais.

\section{Crise de confiança}

Tomemos, no entanto, como ponto de partida a tese principal que emerge dos estudos sociológicos ou politológicos disponíveis. Embora esses trabalhos ofereçam apenas explicações de caráter externo, eles fornecem indicações semioticamente muito

2 Sobre o conceito semiótico de ligação, cf. (LANDOWSKI, 2019b). 
úteis. Os apoiadores de movimentos populistas seriam todos "perdedores da globalização" e "excluídos da revolução digital". O voto deles seria, em outras palavras, aqui e ali a expressão de um mesmo tipo de frustrações ligadas às mudanças tecnológicas e econômicas globais, agravadas em todos os lugares pelo mesmo ressentimento em relação a "elites" consideradas quer incapazes de resolver os problemas causados por essas evoluções, quer demasiadamente atadas a seus próprios interesses imediatos para enfrentá-los com equidade.

Em termos de semiótica narrativa, estamos lidando aqui com uma crise "fiduciária": é a perda de confiança nas figuras políticas e nas instituições que distanciou das formas tradicionais de participação política uma massa de cidadãos vítimas da conjuntura mundial, conduziu uma parte em direção à abstenção e empurrou os mais indignados, os mais revoltados ou os mais resolvidos para o lado de personalidades rejeitadas pela "classe política". Para os eleitores que sonham em afastar do poder os representantes de um "establishment" tido como responsável por seu destino injusto, o que poderia ser mais lógico do que se aliar a "outsiders" que se proclamam os inimigos de toda e qualquer "elite", em nome justamente do "povo"?

No entanto, essa visão em preto e branco e a lógica de exclusão que ela supõe não parecem suficientes. Fora de certos casos de adesão quase mecânica a um candidato pela simples rejeição de seu oponente, geralmente não basta desconfiar de um campo para se juntar ao lado oposto. Deve haver ademais um mínimo de motivos positivos, um impulso, uma sedução, certas afinidades sentidas de maneira forte o suficiente para causar atração. Ora, se se entende facilmente como a confiança é perdida (por exemplo, como aquela depositada em um dirigente pode ser quebrada devido ao não respeito a seus compromissos), é menos simples discernir como ela é conquistada. Sobretudo quando se trata, como é cada vez mais frequente, de concedê-la não a profissionais da política conhecidos há muito tempo, mas a novos postulantes que emergem da "sociedade civil", ou seja, a pessoas demasiadamente distantes das funções de representação e de governo para que se possa saber do que elas seriam capazes, por bem ou por mal, se chegassem ao poder.

No entanto, é precisamente deste tipo de virgindade política que a maioria dos candidatos populistas se vale para atrair os eleitores. Sua arte consiste em transformar em virtude sua relativa falta de experiência, seu não profissionalismo e sua distância em relação aos costumes, à linguagem, ao espírito mesmo das esferas políticas estabelecidas. Esta forma de amadorismo que seria incapacitante para qualquer outro tipo de carreira não impede, hoje em dia - ao contrário - de se tornar prefeito de uma grande metrópole, primeiro ministro ou chefe de estado. De fato, apresentar-se como politicamente novato, como alguém que nunca esteve envolvido nas intrigas da "política política", que não depende de nenhum partido, que não tem qualquer responsabilidade nas falhas dos governos precedentes, é assumir a aparência de um corajoso cidadão "como nós", de uma pessoa afastada dos compromissos e mentiras do "sistema", e, por isso mesmo, vítima ou, pelo menos, observadora ultrajada por seus erros, suas injustiças, seus enganos. 
Essa insistência no pertencimento ao mundo dos humildes em oposição ao dos poderosos, ao "povo" em oposição aos privilegiados, e ao mesmo tempo - porque na boca dos populistas essas ideias andam de mãos dadas - bem enraizado na pátria mãe (em oposição aos estrangeiros, imigrantes ou refugiados, vistos como tomadores de empregos e promotores de insegurança), tudo isso segue na mesma direção. Tais promessas de solidariedade e cumplicidade com os indignados são aparentemente, para esse tipo paradoxal de políticos anti-políticos, a melhor maneira de construir a imagem de candidatos dignos de confiança. Ao vê-los e ouvi-los, tudo sugere que uma vez no poder eles não arriscarão trair nem as vítimas da globalização nem os "deixados para trás" da festa digital que depositam neles suas esperanças de vingança.

\section{Rumo à estesia}

Se a confiança que os líderes populistas inspiram repousa sobre o tipo de elementos que se acaba de evocar - "registo político limpo", posição "fora do sistema", qualidade de "verdadeiro autóctone" ${ }^{3}$-, então deve-se em boa lógica admitir que essa sua confiança não tem como condição necessária uma compreensão aprofundada da política que os distintos partidos propõem ou estão conduzindo nos planos econômico, social, internacional, etc. Pode ser mesmo que uma boa parte de seus eleitores seja ou acredite ser menos capaz do que outros para julgar nestas matérias frequentemente apresentadas como muito técnicas. Pode ser mesmo que eles nem com isso se importem. O fato de isso não impedir que saibam a quem aplaudir reforça a ideia de que o conteúdo preciso dos programas políticos não é o critério principal de suas escolhas: a imagem pessoal do líder prevalece sobre os detalhes de suas propostas.

Mas "imagem" não basta. Esta noção implica uma distância entre aquele que olha e o que ele vê. Ora, na política, não se trata sempre - nem necessariamente - de olhar e de julgar para, em seguida, decidir. Como a simpatia ou a antipatia, a adesão política pode também ser da ordem do impulso espontâneo, "sem razão". Ou, melhor dito, pode se tratar de um impulso que possui sim certas "razões", mas razões sentidas mais do que pensadas e ponderadas, ou seja, baseadas em sentimentos de afinidade imediata que remetem a um plano de pertinência distinto do plano puramente cognitivo. Um elã assim espontâneo, podemos vê-lo se desenvolver diante dos oradores populistas de pelo menos duas maneiras complementares.

Por um lado, à maneira de humores compartilhados. Entre esses, encontra-se um dos componentes afetivos essenciais do ethos populista: é a xenofobia - nem uma posição ideológica nem uma opção refletida, mas uma compulsão de rejeição de fundo emocional e mesmo somática, "visceral". Para um líder sem escrúpulos, dar a seus apoiadores a oportunidade de comungar no ódio dos outros, eis aí um meio poderoso de arrebanhar

3 Universalisando o nome do partido populista finlandês, "Os verdadeiros Finlandeses". 
simpatizantes em torno de sua pessoa. Daí o interesse dos demagogos em excitar, para além da execração das "elites", as pulsões com conotação racial, mesmo que essas não sejam prerrogativas apenas dos círculos "populares". Quando se trata de partilhar o sentimento de se diferenciar juntos em frente dos "invasores" ao ponto de "não poder senti-los" (o que significa execrá-los como corpo até o fundo do seu próprio corpo), a devoção ao chefe deve-se apenas a um puro sentir, o mais bruto e o mais brutal. Sobre esse aspecto, o modelo histórico insuperável é o discurso de comício hitleriano. Nesse, o que conta é menos a argumentação que busca motivar o ódio (como uma paixão baseada em pretensas boas razões de odiar) do que o tom, o gesto, o ritmo, a fantástica dinâmica corporal de um orador capaz de fazer partilhar o ódio, de fazê-lo viver enquanto moção somática induzida contagiosamente.

Mas por outro lado, a confiança se funda também, mais pacificamente, na exaltação das similitudes entre si. O mais elementar a este respeito é a certeza de se encontrar entre próximos, do mesmo mundo e do mesmo lado. Ora, um dos principais talentos dos líderes populistas é precisamente saber se fazer passar por próximos de sua clientela. Para muitos entre eles, uma presença contínua nas redes sociais se tornou, como é sabido, o meio mais eficaz para manter com seu público um laço de familiaridade, por assim dizer, íntimo ${ }^{4}$. Paralelamente, ao evidenciar que eles se comportam "como todo mundo" na vida de todos os dias, suas aparições nas telas grandes e pequenas atestam a cada instante que eles compartilham de "nossas preocupações", e que, se assim o fazem, é porque eles também são "do povo" ${ }^{5}$. Expressar-se com a mesma linguagem coloquial que "você e eu" é prova disso. Alguns vão mesmo mais longe, passando da familiaridade a uma grosseria calculada para escandalizar a "boa sociedade" (as pessoas "de cima") ao mesmo tempo que encanta seus seguidores. Vale dizer que na cena política, saber escandalizar por um discurso cuja insolência cauciona a "verdade" e assegura a cumplicidade das pessoas supostamente "de baixo", isso também faz parte das competências do bufão .

Fundada sobre tais elementos, a credibilidade de um líder não depende nem da viabilidade de seus projetos nem da coerência ou da veracidade de suas propostas. Uma vez que é uma simpatia à flor da pele para a própria pessoa que atrai a adesão dos apoiadores àquilo que ele enuncia, nem a demagogia de suas promessas nem a falsidade eventual de suas afirmações o podem prejudicar. Para aqueles que ele fascina, não pode haver de sua parte nem discurso falso nem palavra delirante. Nenhuma refutação, nenhum fact-checking poderão, nestas condições, ser credíveis, nem mesmo escutados. Não que eles sejam considerados, por sua vez, falsos, mas, muito mais radicalmente, porque,

4 Sobre o modo de presença política na era do "bolsonarismo", ver (FECHINE, 2020).

5 Cf. (DEMURO e SEDDA, 2020).

6 Comediante, palhaço, histrião, ou bufão? Falstaff, Ubu, Coluche... Trump, Johnson, Bolsonaro, Grillo, Le Pen... toda uma linhagem profissional, dos maiores aos menores, atesta que esses termos não têm nada de inapropriado. Sobre o bom uso da grosseria em política em relação com as formas de popularidade, cf. "A vedete e o bufão" in (LANDOWSKI, 2002, cap. 7). 
aos olhos dos fiéis, eles não podem ser relevantes enquanto atos de linguagem: por definição, contra a palavra do depositário de uma confiança cega, nenhuma argúcia é admissível.

Este predomínio dos humores é o ponto final de uma mudança radical de atitude epistêmica. Uma forma de discursividade feita de rigor argumentativo perdeu sua pregnância, ao passo que, ao lado dela, mas também, em grande parte, no seu lugar, o sensível, o "estésico" conquistou um papel preponderante 7 . Isto não significa, obviamente, que o poder de encantamento dos oradores populistas seja por si só suficiente para ganhar os votos de qualquer auditório. Os seus discursos só podem desempenhar eficazmente seu poder de sedução sobre aqueles cuja visão de mundo os predispõe a acreditar nas soluções milagrosas que promete o demagogo visto como um salvador. Sem um mínimo de predisposições desta ordem, que por natureza remetem ao plano cognitivo, o charme exercido no plano estésico não funcionaria. Mas por pouco que elas forem reunidas, então um timbre de voz, uma expressão fisionômica, uma gestualidade singulares, um tom, um ritmo, a virtude contagiosa de uma forte "presença" podem servir como pontos de cristalização para a formação de laços provados como se fosse de pessoa a pessoa e olhos nos olhos ${ }^{8}$.

\section{Regimes semióticos e regimes políticos}

Durante muito tempo, nas regiões do mundo atualmente dominadas ou fortemente ameaçadas pelo populismo, reinou uma perfeita concordância entre o regime jurídicopolítico da representação, ou "democracia representativa", e o regime semiótico denominado de manipulação, em que os processos de persuasão recíproca conduzem a acordos entre os sujeitos. O eleitor-cidadão, como o herói da narrativa semiótica canônica, era, pelo menos em teoria, um sujeito autônomo, guiado pelo princípio de intencionalidade, dotado de vontade e de razão. Consciente de si mesmo e dos seus interesses, ele decidia tudo com conhecimento de causa, sabendo pesar o pro e o contra e estimar o justo valor dos "valores". Mesmo seus impulsos passionais obedeciam a uma forma de racionalidade que os tornavam sensatos e, grosso modo, previsíveis. O homo politicus (e seu irmão o homo economicus), tal como o homo semioticus, era essencialmente um actante-sujeito cognitivamente competente - um espírito "inteligente".

Depois, na teoria, apareceu não o seu contrário (já que um agente sem discernimento nem vontade não seria mais, propriamente dizendo, um "sujeito") mas seu complementar: um sujeito encarnado, permeável, corpo e alma, às qualidades estésicas do mundo e às presenças humanas que ocupam sua vizinhança - numa palavra, um sujeito "sensível". O reconhecimento do princípio de sensibilidade, assim integrado no interior de um modelo interacional alargado, conduziu a por em evidência, ao lado do regime

7 Sobre a noção de estesia introduzida na semiótica por A.J. Greimas, cf. (2017).

8 Cf. "Diana, in vivo", in (LANDOWSKI, 2004, cap. 10). 
da manipulação fundado sobre o princípio da intencionalidade, um regime de sentido e de interação bem diferente e até então semioticamente desconhecido, aquele do ajustamento. Mas à manipulação e ao ajustamento, o modelo interacional que propomos articula dois outros regimes: aquele da programação, fundado sobre o princípio de regularidade, e aquele do acidente, caracterizado, ao contrário, pela ausência de toda regularidade, dito de outro modo, regido pelo princípio de aléa ${ }^{9}$.

Separadamente ou combinados uns com os outros, esses diversos regimes permitem dar conta da dimensão significante da interação na maior variedade de domínios. No âmbito que nos interessa aqui, a cada um deles corresponde um tipo determinado de regime político:

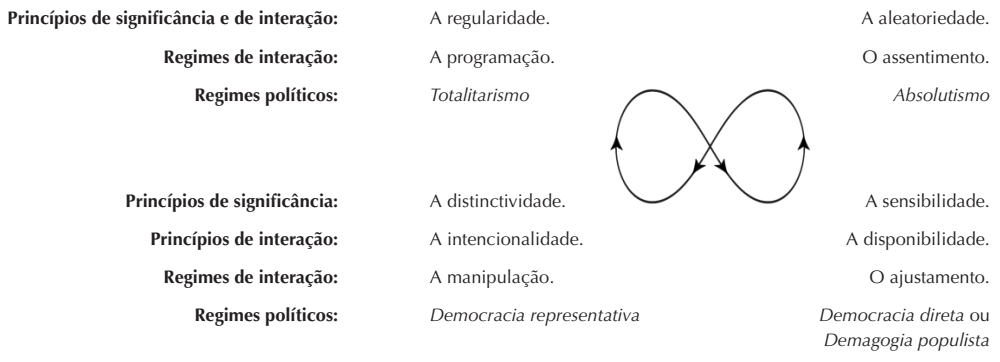

Os totalitarismos são regimes políticos nos quais toda a coletividade está submetida a princípios rígidos e regularidades teoricamente imutáveis, em geral baseadas num pretenso conhecimento científico das "leis" da sociedade e da economia. As interações entre agentes são, por conseguinte, enquadradas e orientadas por planificações que têm por efeito reduzir os comportamentos individuais e coletivos à execução de algoritmos preestabelecidos: em termos semióticos, é a sintaxe do regime interacional da programação que vigora. Do corporatismo da França de Vichy (sob a ocupação alemã) à ordem social nazi, fascista ou stalinista, os exemplos históricos deste tipo de regimes amplamente apoiados pelas massas, e, nesse sentido, "populares", são demasiado conhecidos para que seja necessário entrar em pormenores. Em contrapartida, a cada dia nos parece mais urgente, hoje, mensurar o quanto, e com que velocidade vão na mesma direção as atuais formas de normalização tornadas possíveis pelo desenvolvimento dos instrumentos de vigilância informática. Mediante novos dispositivos de controle individual em grande escala, elas nos prometem, a breve prazo, um totalitarismo talvez de aparência mais "soft" do que certas formas policiais de outrora, mas tanto mais eficaz quanto serão mais bem aceitas, senão mesmo desejadas, pela massa da população ("populista", inclusive) ${ }^{10}$.

Não menos rígidos e coercivos, embora de outra forma, os absolutismos colocam os sujeitos políticos sob a dependência de uma autoridade toda poderosa, cujas decisões

9 Sobre os princípios fundadores do modelo interacional, cf. Interações arriscadas (LANDOWSKI, 2014 a). Por uma apresentação abreviada, (idem, 2014b). Por uma apresentação atualizada, (idem, 2019a: 6-25).

10 Perspectiva desenvolvida a propósito das armadilhas do numérico em (idem, 2016). 
dependem apenas do seu próprio capricho: é a vontade soberana e arbitrária do príncipe que determina a sorte de cada um sob a forma de diktat tão difíceis de antecipar como os acidentes da vida ordinária. A autoridade não se funda mais sobre uma "ciência" da sociedade, mas sobre um dogma, tal aquele da transcendência do poder "de direito divino" investido na autoridade suprema do tempo das antigas monarquias. Que se trate do monarca no sentido próprio, ou, na época moderna, de figuras do poder investidas de uma sacralidade laica (desde o "Pequeno Pai dos Povos" ou o "Grande Timoneiro"11 de outrora até aos diversos "homens providenciais" atualmente venerados pelos populistas um pouco por todo o mundo), as decisões tomadas por tais dirigentes são a expressão de um poder quase discricionário. Em consequência, suas escolhas não são mais previsíveis do que os "decretos" do acaso. O regime semiótico que daí resulta para os sujeitos é, portanto, o do acidente inevitável - e ao mesmo tempo, possivelmente, o do assentimento ao arbitrário da autoridade suprema. De fato, muitas vezes, o que se pode fazer diante do absoluto do poder, senão consentir-lhe como uma fatalidade? Se o "culto da personalidade" constituiu outrora, em vários países, uma das formas mais notórias de um tal assentimento, atualmente é ao mesmo regime que remete a devoção manifestada por milhões de apoiadores de indivíduos tão "caprichosos", senão mesmo lunáticos, como um Donald Trump, um Boris Johnson ou um Jair Bolsonaro.

Como cada um pode observar, não há nenhuma forma, passada ou atual, de totalitarismo ou absolutismo que não seja hoje formalmente rejeitada pelo conjunto dos partidos ou movimentos políticos: todos, incluindo os ditadores tanto quanto os populistas, se proclamam "democratas". É verdade que este termo não é, em si mesmo, de grande clareza, uma vez que, no passado, se conheceu "democracias populares" de caráter tipicamente totalitário e que se multiplicam atualmente "democracias iliberais" de forte tendência absolutista (como na Hungria, na Polônia ou na Itália). Mas na presente conjuntura política, o debate se concentra essencialmente em torno da distinção entre duas formas de "democracia", uma dita "representativa", a outra "direta". Essa última, graças aos meios informáticos mais modernos, permitiria uma participação de todos os cidadãos na tomada de decisão, sem passar pela intermediação de representantes eleitos (um pouco conforme o modelo da ágora ateniense, do tempo de Péricles).

Em termos da semiótica da interação, a democracia representativa, tal como tradicionalmente praticada nos países ocidentais, constitui, como nós já apontamos acima, uma exemplificação perfeita do regime da manipulação. Ora, como se sabe, os populistas se declaram explicitamente os adversários dessa concepção, e se proclamam os promotores da forma alternativa. Quer isto dizer que, pelo simples fato de eles se oporem à democracia na sua forma mais clássica, os populistas, ao pretender instaurar em seu lugar uma democracia direta, propõem um regime político que, semioticamente falando, remeteria ao regime interacional oposto àquele da manipulação, o do ajustamento? Tomado

11 N.T. Na Union Soviética, a denominação afetuosa de Pequeno Pai dos Povos era usada para designar Stalin, com fins de propaganda política. Grande Timoneiro era empregado como sobrenome de Mao Tse Toung. 
ao pé da letra, o diagrama acima poderia fazê-lo crer. Contudo, a resposta só pode, na realidade, ser negativa. Isto requer algumas explicações.

\section{Perigo da estesia}

Acreditamos que uma forma de organização da vida política articulada conforme o tipo de sintaxe interacional que rege o que chamamos de "ajustamento" entre sujeitos é possível, teorica e praticamente. Aliás, aos nossos olhos, é isso mesmo que mereceria a nobre designação de "democracia direta". Mas a forma de democracia proposta pelos populistas é dessa uma caricatura. O que recobre, então, o conceito de ajustamento, e em que é que a demagogia populista o deturpa?

O ajustamento, do modo como o entendemos, não deve ser confundido com a adaptação (ou a acomodação), que remete à programação - regime no qual um actante só pode agir sobre um outro na condição de respeitar as regularidades que regem seu comportamento. Ele não consiste tampouco - por contraste com a manipulação - em fazer de modo que um dos actantes aceite de conformar-se, mesmo que de má vontade, à vontade do outro. Com efeito, o ajustamento é um regime de interação entre iguais. Ademais, ao contrário do manipulador, sujeito intencional que sabe de antemão o que ele quer e manipula o outro na firme intenção de obter o que ele almeja adquirir, o sujeito do ajustamento é essencialmente um sujeito disponível. Por "disponibilidade", nós entendemos uma disposição actancial e modal voltada em direção não à apropriação do mundo mas ao desabrochamento do potencial das coisas, dos outros sujeitos, e de si mesmo. Um sujeito "disponível", portanto, não cobiça a priori nada de particular, nem poderes, nem honras, nem mulheres, nem riquezas... Ele só aspira viver e, se possível, desenvolver-se: é um ser aberto a tudo o que se apresenta, ao próprio presente e aos outros.

Quando uma tal disponibilidade é recíproca entre dois parceiros, suas relações podem tomar a forma de um processo de co-criação de sentido e, por assim dizer, de reinvenção da vida. A interação não estando nesse caso exaustivamente enquadrada por rígidos determinismos ou regras sociais coercitivas (como na programação), mas também não inteiramente dependente do acaso (como sob o regime do acidente-assentimento), nem mesmo constantemente suspensa em difíceis negociações entre intenções divergentes ou interesses opostos (como na manipulação), a vida pode então ser concebida, ou ao menos sonhada, como uma aventura gratificante - livre e criativa -, uma aventura na qual, na imanência das relações entre entidades interdependentes e sensíveis umas às outras ao mesmo tempo que respeitosas de sua autonomia respectiva, cada um procura realizar-se mediante a realização correlativa (o "desabrochamento") do potencial próprio ao outro ou aos outros. Se isso aplica-se tão bem, por exemplo, à amizade, é porque a amizade põe em jogo uma dinâmica de incitações recíprocas graças às quais os parceiros criam entre eles uma relação sem visada nem regras preestabelecidas, mas que possibilita a invenção 
de um modo de ser, de pensar e de viver junto de caráter inédito ${ }^{12}$. Sob sua forma ideal, eis o que é o ajustamento entre sujeitos disponíveis. Não há dúvida que tal ideal esteja muito distante do universo autoritário e xenófobo do populismo!

No entanto, numerosos estudos semióticos têm mostrado que um tal regime é aplicável ao funcionamento da vida social, econômica e política. Por exemplo, num estudo recente que tem por objeto umas empresas organizadas sob a forma de cooperativas, o autor (sem utilizar o termo mesmo de ajustamento) mostra qual revolução cultural e política o recurso a uma tal sintaxe é susceptível de introduzir no funcionamento social dos órgãos de produção econômica e no vivido cotidiano de seus agentes (FONTANILLE, 2018). Outros trabalhos indicam em que condições pode acontecer o mesmo em domínios da prática mais diversos, do desporto (DEMURU, 2015) à educação (LANDOWSKI, 2015), do design (SCOZ, 2018) à conversação (BARROS, 2017), da investigação (PETITIMBERT, 2017) à oração (PETITIMBERT, 2015 e 2016), ou ainda em matéria de gestão de coletividades públicas ou privadas (CIACO, 2013; CERVELLI, 2013; PETITIMBERT, 2013; CATELLANI, 2018). Conduzindo a uma ecologia do sentido, a lógica do regime de ajustamento oferece mesmo, em nossa opinião, uma via de reflexão alternativa sobre os dramáticos problemas ambientais e sociais de nossa época (LANDOWSKI, 2017; CALAME, 2015).

Mas, quer seja no plano microsocial, quer num plano mais amplo, as formas de democracia direta analisadas por esses diversos estudos só são possíveis respeitando ao mesmo tempo ambos os princípios sem os quais nenhuma verdadeira sintaxe de ajustamento pode se desenvolver: o de sensibilidade, sem dúvida, mas também o de disponibilidade. Infelizmente, do regime de ajustamento assim definido, os populistas apenas tomam o que lhes convém, a saber, unicamente o lado sensível. Ora, apoiar-se exclusivamente no contágio do sentir, valer-se apenas de uma presença contínua, instante a instante, nas redes sociais, é transformar a coletividade numa "massa tímica" indiferenciada, amorfa e maleável, abrindo o caminho às piores formas de escravidão ${ }^{13}$. Como se diz, o tribuno "eletriza" as massas: os corpos através dos quais passa a sua potência energética são seu "fio condutor", se bem que, de um corpo a outro, o fervor popular se alastra para todas as direções ${ }^{14}$. No que refere à "democracia direta", não resta senão um slogan de valor conotativo e, além disso, enganador.

Por isso, quando introduzimos, sob o nome de "contágio", a dimensão sensível entre as variáveis da relação intersubjetiva, distinguimos imediatamente dois usos possíveis, bilateral ou unilateral (LANDOWSKI, 2004, p. 130-133). O uso unilateral equivale à aniquilação do outro enquanto sujeito, por absorção ou fusão. A exploração do sensível pode então ser posta a serviço da "manipulação", não unicamente no sentido convencionalmente admitido entre semioticistas (manipular, nesse quadro, é persuadir de

12 Sobre amizade e ajustamento no contexto etnográfico, cf. (LANDOWSKI, 2008a).

13 Sobre a gestão populista da presença contagiosa, cf. (LANDOWSKI, 2002, p. 204-206; 2004, p. 210-213; 2008b).

14 No que refere à abordagem semiótica das noções de propagação e de alastramento, cf. respectivamente (FECHINE, 2018; LANDOWSKI, 2004: 113-124) e (LANDOWSKI, 2014c). 
modo a fazer fazer conforme algum acordo contratual) mas também segundo a acepção usual e pejorativa, isto é, submeter o outro a si mesmo atuando sobre seu corpo, como na hipnose que reduz o outro a um não sujeito programado, ou sobre suas pulsões, tal a publicidade que "faz desejar" por contágio sensível (LANDOWSKI, 2006, p. 15-30).

A propaganda atual não faz outra coisa. Apostando tudo na estesia a ponto de conseguir fazer passar as fake news as mais rocambolescas por verdades estabelecidas, ela parece neutralizar as faculdades de raciocínio de muitos de nossos contemporâneos. No entanto, contrariamente ao que a candidata democrata às eleições presidenciais norte-americanas de 2016, Hillary Clinton, um dia desajeitadamente insinuou, os eleitores seduzidos pela retórica de pelotiqueiro e as piscadelas de seu adversário não eram, constitutivamente, menos capazes de julgamento do que os outros: também eles eram, como todos nós, sensíveis e inteligentes. O fato de que eles estavam estesicamente receptivos à sedução encantatória e capilar de seu herói, e que, correlativamente, Ihes parecia insuportável a hexis de sua rival, tipo "mulher certinha" (ou "dondoca", teriam talvez dito alguns entre seus detratores, com sua soberba de impecável em todos os pontos "como é necessário", do penteado ao sapato), isso não os impedia, por outro lado, de avaliar cognitivamente diversos aspectos menos "epidérmicos" da situação. E, no entanto, neste caso, foi a lógica do sensível que prevaleceu sobre o peso dos argumentos e que embasou a decisão no jogo das atrações e das repulsões imediatas.

O fato que o cognitivo e o estésico, longe de se excluirem um ao outro, sejam ao contrário, em teoria, conjuntamente presentes na base de todas nossas escolhas, aí compreendidas as políticas, não impede, portanto, que, apesar de tudo, em certos contextos, eles tendam a neutralizar-se mutuamente. É isto que permite compreender que uma campanha eleitoral e mesmo uma estratégia de comunicação a longo prazo possam, a seu critério, apoiar-se preferencialmente numa ou noutra destas duas facetas da nossa compreensão do mundo. Mas não se falaria de populismo se os grandes e os pequenos palhaços do nosso tempo não tivessem feito há muito a sua escolha.

Eric Landowski é pesquisador do CNRS.

eric.landowski@sciencespo.fr

\section{Referências}

BARROS, D. Les régimes de sens et d'interaction dans la conversation. Actes Sémiotiques, v.120. Université de Limoges, 2017.

CALAME, C. Avenir de la planète et urgence climatique: Au-delà de l'opposition nature / culture. Fécamp, Lignes, 2015. 
CATELLANI, A. L'entreprise responsable et ses parties prenantes: entre manipulation et co-construction de sens. Actes Sémiotiques, v. 122, 2018.

CERVELLI, P. Fallimenti della programmazione e dinamiche dell'aggiustamento. Sull'auto-produzione dello spazio pubblico in una periferia di Roma, in OLIVEIRA, A. C. (ed.). As Interações sensíveis: Ensaios de sociossemiótica a partir da obra de E. Landowski. São Paulo, Estação das Letras e Cores, 2013.

CIACO, J. A inovação em discursos publicitários: semiótica e marketing. São Paulo, Estação das Letras e Cores, 2013.

DEMURU, P. Malandragem vs. Arte di arrangiarsi: Stili di vita e forme dell'aggiustamento tra Brasile e Italia. Actes Sémiotiques, v. 118, 2015.

; SEDDA, F. Il corpo social-ista. Actes Sémiotiques, v. 123, 2020.

FECHINE, Y. Pour une sémiotique de la propagation: invention et imitation sur les réseaux sociaux. Actes Sémiotiques, v. 121, 2018.

Passions et présence dans le populisme numérique brésilien. Actes Sémiotiques, v. 123,2020 .

FONTANILLE, J. La coopérative et son territoire. Terres de sens. Limoges, PULIM, 2018.

GREIMAS, A. J. Da Imperfeição. São Paulo, reed. Estação das Letras e Cores, (2017 [1987]).

LANDOWSKI, E. Presenças do outro. São Paulo, Perspectiva, (2002 [1997]).

. Passions sans nom. Paris, Presses Universitaires de France, 2004.

. O triângulo emocional do discurso publicitário. Comunicação Midiática, v.6, 2006.

L'épreuve de I'autre. Sign Systems Studies, 34.2, 2008a.

. La politique-spectacle revisitée: manipuler par contagion. Versus, v.107, 2008b.

Interações arriscadas. São Paulo, Estação das Letras e Cores, (2014a [2005]).

Sociossemiótica : uma teoria geral do sentido. Galáxia, v. 13, 27, 2014 b.

Pour A. In: FECHINE, Y. (org.). Semiótica nas práticas sociais. São Paulo, Estação das Letras e Cores, 2014c.

. Regimes de sentido e formas de educação. EntreLetras, 7, 2, (2016a [2015]). Disponível em:

$<$ https://sistemas2.uft.edu.br:8004/index.php/entreletras>.

. Pièges: de la prise de corps à la mise en ligne. Carte Semiotiche, 4, 2016b.

. Petit manifeste sémiotique. Actes Sémiotiques, v. 120, 2017.

Populisme et esthésie. Actes Sémiotiques, v. 121, 2018. Disponível em : <http://epublications. unilim.fr/revue s/as/6021>.

Politiques de la sémiotique. Rivista Italiana di Filosofia del Linguaggio, 13, 2, pp. 6-25, 2019a. Disponível em: <http://www.rifl.unical.it/index.php/rifl/issue/archive>.

. Antes da interação, a ligacão. Documentos de estudo do Centro de Pesquisas Sociossemióticas, 9. São Paulo, CPS editora, (2019b [2005]).

PETITIMBERT, J.P. La précarité comme stratégie d'entreprise. Actes Sémiotiques, v. 116, 2013. v. 118,2015

Lecture d'une pratique et d'une interaction: I'hésychasme orthodoxe. Actes Sémiotiques,

Les traductions liturgiques du Notre Père. Actes Sémiotiques, v. 119, 2016. 
.Régimes de sens et logique des sciences. Interactions socio-sémiotiques et avancées scientifiques. Actes Sémiotiques, v. 120, 2017.

. Anthropocenic Park : humans and non-humans in socio-semiotic interaction. Actes Sémiotiques, v. 120, 2017.

SCÓZ, M. Por uma abordagem sociossemiótica do design de interação. Actes Sémiotiques, v. 121, 2018.

Artigo recebido em 01/03/2020

e aprovado em 20/04/2020. 